\title{
Cytopathology of adenovirus keratitis by replica technique
}

\author{
Prabhat C Maudgal
}

\begin{abstract}
Corneal replicas were made from the severely affected eyes of 12 patients presenting with typical signs and symptoms of epidemic keratoconjunctivitis. Adenovirus was isolated from the eyes. Histopathological study of the replicas and cytology of diseased cells removed with the replica showed diffuse mild oedema of the epithelium, with scattered moderately swollen and deformed cells. The clinically observed punctate lesions histologically consisted of markedly swollen cells that had become oval or rounded. Fusion of these cells led to small syncytial formations, and the development of pseudopodia-like processes was occasionally observed. Loss of cell contents resulted in the formation of plicae on the surface of many cells. Two types of inclusion bodies were detected in the epithelial cells. The first type, intranuclear vacuolar inclusions, contained homogeneous material. The second type of inclusions were round, dense bodies, that developed in the homogeneous material of intranuclear vacuolar inclusions. The dense bodies contained the replicating and maturing virus particles. After cell degeneration the dense bodies become extracellular. Making a corneal replica had a beneficial effect on the clinical course of adenovirus keratitis.
\end{abstract}

The in vivo corneal replica technique ${ }^{1-3}$ was developed to study the histopathology of superficial corneal lesions in different types of keratitis without disturbing the exact position of the epithelial cells in relation to each other, as this technique permits us to make an imprint of the corneal surface. In addition, in contrast to the normal cells, diseased superficial cells are easily removed with the replica. Flat mounts of these cells allow study of their cytological details. ${ }^{\star}$

Previous reports on this technique from our laboratory have described the histology and histochemistry of normal superficial corneal epithelium, ${ }^{4}$ the replicative stages of the herpes simplex virus type 1 (HSV-1) in vivo, ${ }^{5}$ and the

^The term 'replica' is used because primarily an imprint of the corneal surface is obtained with this technique. The removal of diseased cells is a secondary phenomenon. Only grossly altered cells come off with the replica. The normal corneal surface cells can be stripped off only by modifying the technique. To understan the difference consider the following: Fig 2 is mainly an imprint, therefore a replica. Only a few cells, like those shown in Fig 6 were present in this are after dissolving the replica. Figs 3 and we prent ins 3 and 4 puncte punctate lesions surrounded 5 is a low power photomicrograph of a flat mount that shows the number or 'diseased cells' forming several punctate lesions. Only a few scattered 'diseased cells' came off with the replica in the are intervening between the punctate lesions. Comparison of these photographs demonstrates the small number of cells that are actually obtained with this technique. Although the number of cells in flat mounts is small, we can stain them by conventiona techniques. The replicas cannot be stained. morphological and histochemical alterations in the HSV-1 infected rabbit epithelium. ${ }^{6}$ These studies have not only confirmed the observations on $\mathrm{HSV}-1$ replication in vitro, ${ }^{7}$ they have also further elucidated the process of virus release from the cells after viral multiplication. Similar cytopathological alterations were detected when human dendritic and punctate lesions were investigated by means of corneal replicas. ${ }^{89}$

In this paper the cytopathology of adenovirus keratoconjunctivitis (epidemic keratoconjunctivitis) is presented. The results will be discussed in relation to the similarities to or distinguishing features from the histopathology of human dendritic and punctate herpetic keratitis, also studied by the replica technique.

\section{Subjects and methods}

Corneal replicas were made from the more severely affected eye of 12 patients who presented with the typical signs and symptoms of epidemic keratoconjunctivitis. The criterion of patient selection was the presence of epithelial punctate corneal lesions (Fig 1). Before the replica was made conjunctival swabs were taken for virus culture, and conjunctival scrapings were made. The scrapings were stained with Giemsa stain and examined by light microscopy. The technique of making a replica has been described in detail elsewhere. ${ }^{1-3}$ In short, the procedure is as follows: (a) instil one drop of a topical anaesthetic three times at five minute intervals; $(b)$ keep the eye open with an ocular speculum; (c) dry the tear film by blowing air for about one minute; $(d)$ paint a thin layer of collodion in amyl acetate (3\%-4\% solution, w/v)

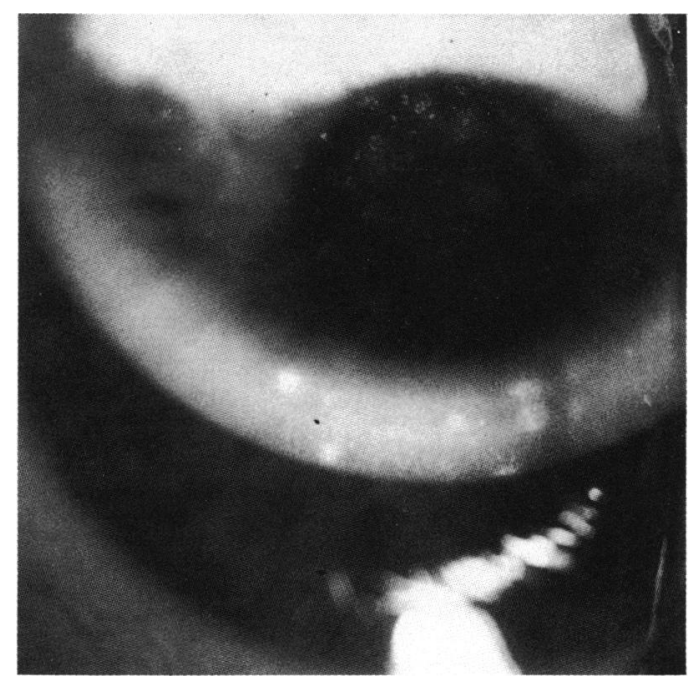

Figure 1 Punctate lesions on the cornea in epidemic keratoconjunctivitis caused by adenovirus. There is some subepithelial opacification. 


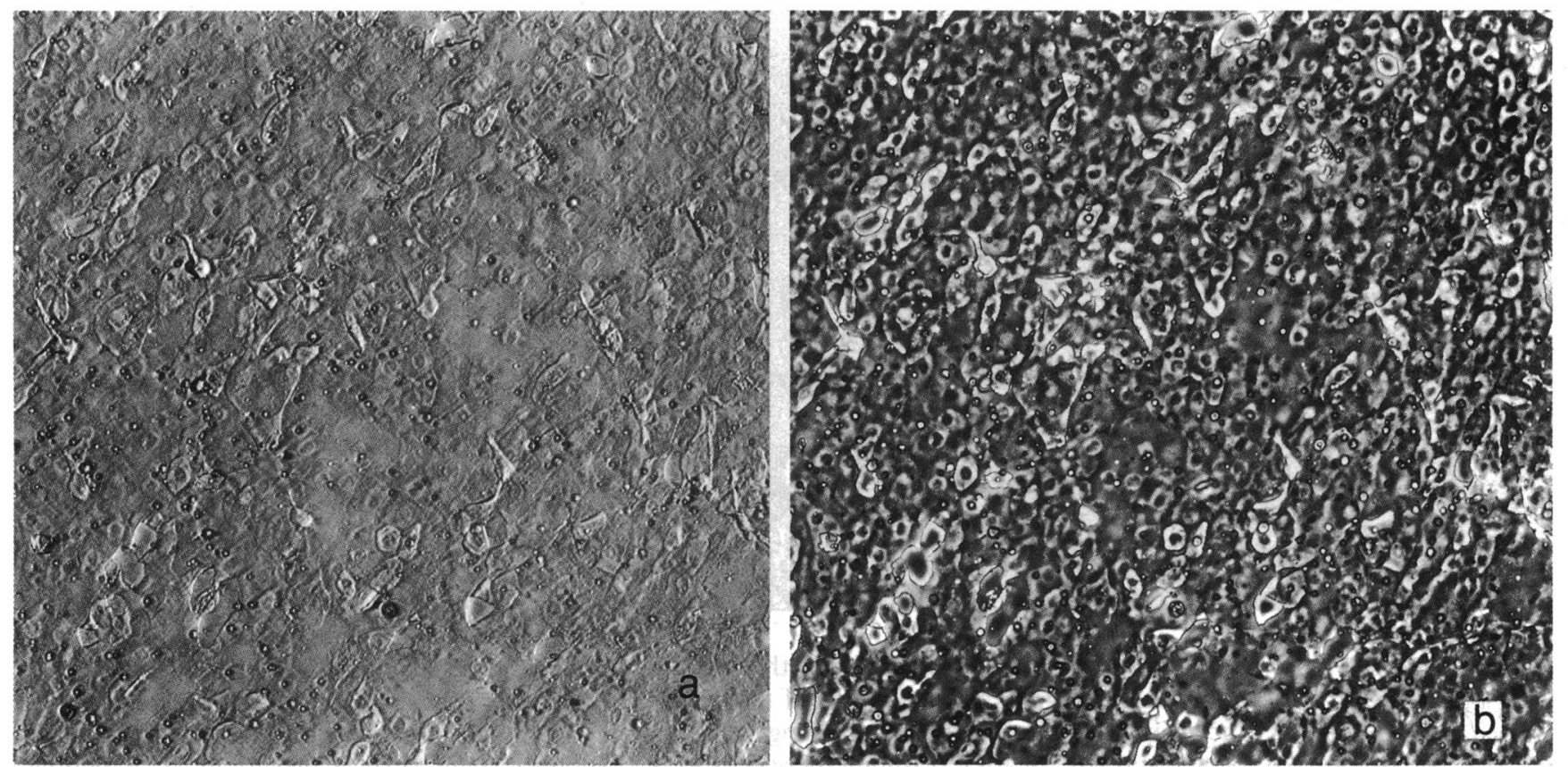

Figure 2 Scattered moderately swollen epithelium cells show morphological alterations. The cells have a tendency to become round. Small round dots are artefacts in the replica (a) Oblique illumination microscopy. (b) Phase contrast microscopy. $(\times 180)$

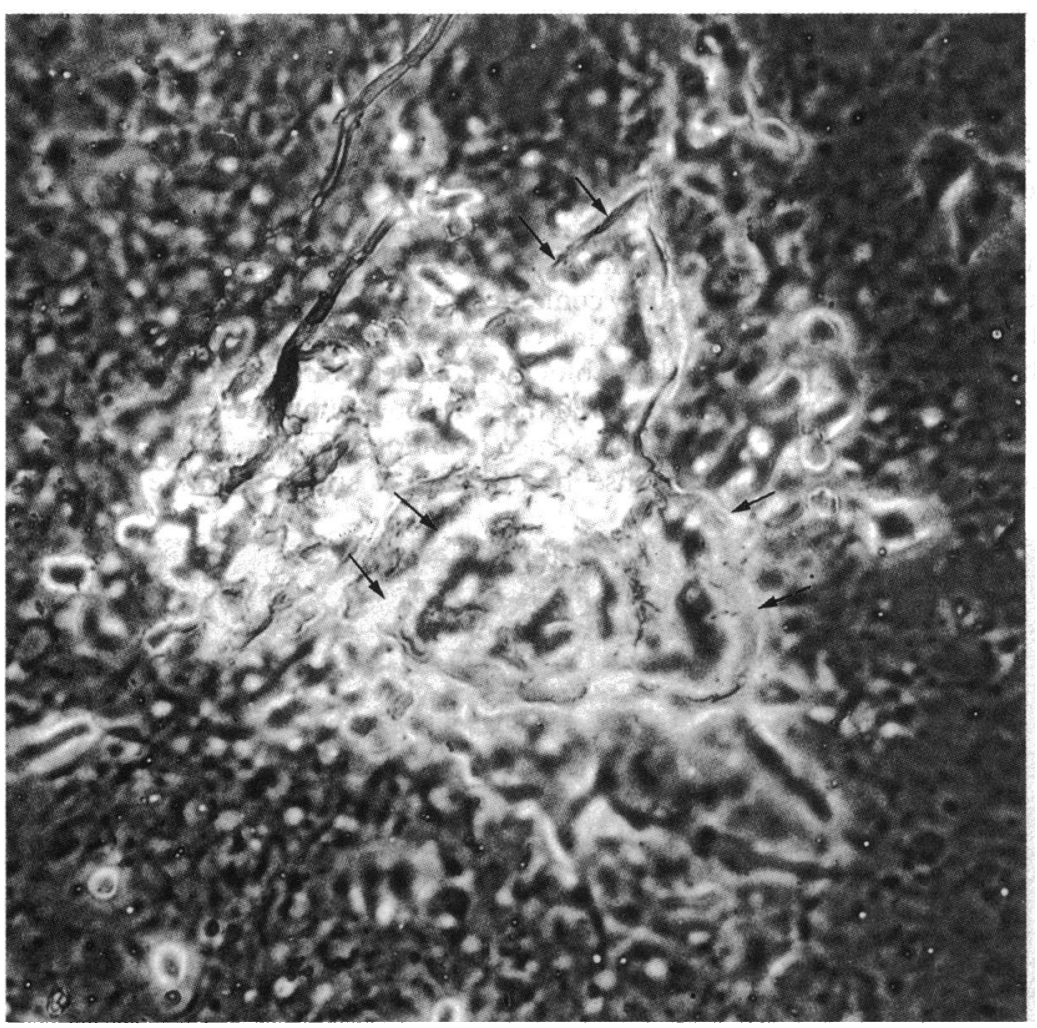

Figure 3 A focal punctate lesion appears bright in contrast to the surrounding cells. The lesion is formed by markedly swollen cells and syncytia (arrows). The borders of the lesion are irregular and not circumscribed. Phase contrast microscopy of the replica $(\times 180)$ collodion membrane formed on the cornea (this on the cornea; (e) dry the painted solution by blowing air for about two minutes; $(f)$ peel off the is the replica of the corneal surface); $(g)$ mount the membrane (replica) on clear glass slide in $0 \cdot 1 \%$ albumin, with the epithelium side down. Normal cells or slightly altered cells are not removed with the replica.

After making the replica antibiotic ointment was put in the eye and a pressure bandage applied for 48 hours. Generally, the epithelial wound created by the replica became re-epithelialised in this period. If a small epithelium defect remained, the eye was patched for another 24 hours.

The corneal replicas were examined by phase contrast and oblique illumination microscopy. ${ }^{12}$ After dissolving the collodion membrane of the replica in acetone, the flat mounts of unstained diseased epithelial cells were again studied by these microscopic techniques. Subsequently, the cells were stained with haematoxylin-eosin, toluidine blue, or Giemsa stain. Some slides were first examined by a direct immunofluorescence technique, using fluorescein labelled antibodies against adenovirus, and then stained by one of the above methods.

\section{Results}

Punctate lesions did not reappear in the healed epithelium in nine patients after the replica was made. In three patients one to three punctate epithelial lesions developed, which disappeared within one week. There was no significant subepithelial opacification at the site of these lesions. In every patient punctate epithelial lesions in the untreated second eye persisted for 10 to 14 days, and marked subepithelial opacities developed at the site of epithelial lesions. These opacities did not disappear for several weeks or several months.

\section{VIRUS CULTURE}

Adenovirus was isolated from all eyes.

\section{CYTOPATHOLOGY}

Scrapings. Giemsa stained conjunctival scrapings showed a large number of lymphocytes and degenerated conjunctival epithelium cells with nuclear vacuolation. Inclusion bodies were not found in the material scraped from the conjunctiva.

Replicas. Phase contrast microscopy and 


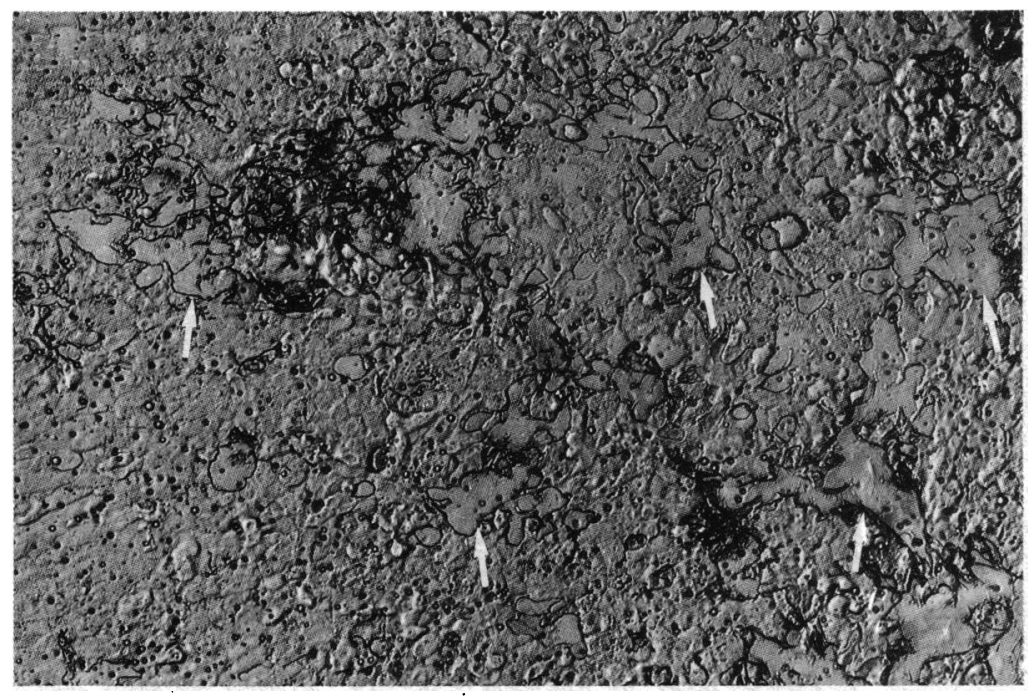

Figure 4 A diffuse epithelial lesion showing rounded, markedly swollen, epithelium cells. Some syncytia are indicated by arrows. Small round dots are artefacts. Oblique illumination microscopy. $(\times 150)$

Figure 5 Flat mounts of diseased cells in punctate lesions after dissolving collodion membrane.

(Haematoxylin-eosin, $\times 45$ ) acetone, flat mounts of diseased cells were first examined unstained and then again after staining. Most of the cells removed with the replica belonged to the areas of punctate lesions (Fig 5).

Cells from the punctate lesions showed stronger staining of their nuclei and cytoplasm than observed in normal epithelium cells, indicating a rise in their nucleoprotein content. In all replicas alterations in cell membrane were noted in many cells, which showed plicae on the cell surface by oblique illumination microscopy or dark lines by phase contrast microscopy (Fig 6). With the latter technique part of such a cell that had developed surface plicae appeared lighter than the rest of the cell. In stained slides this part of the cells was faintly coloured. These observations suggest that viral infection induces loss of cell contents, resulting in shrivelling of the cell walls. In fact, in many specimens empty envelopes of cell membranes devoid of any detectable cell contents were observed.

In other cells, especially at the periphery of the syncytia, oblique illumination microscopy showed small surface elevations, like pebbles projecting from the surface (Fig 6). By phase contrast microscopy of unstained cells, and light microscopy of stained slides, these surface elevations were found to be caused by cytoplasmic vacuoles. The nuclei of many cells also contained different sized vacuoles, whereas round dense bodies were present in other cells. Sometimes the dense bodies were located inside the nuclear vacuoles.

The intranuclear vacuoles appeared empty by haematoxylin-eosin stain (Fig 7), except when they contained round dense bodies, but toluidine blue and Giemsa staining showed the presence of light blue homogeneous material in them. This material did not show fluorescence by immunofluorescence technique. The intranuclear round dense bodies gave a strong positive immuno-

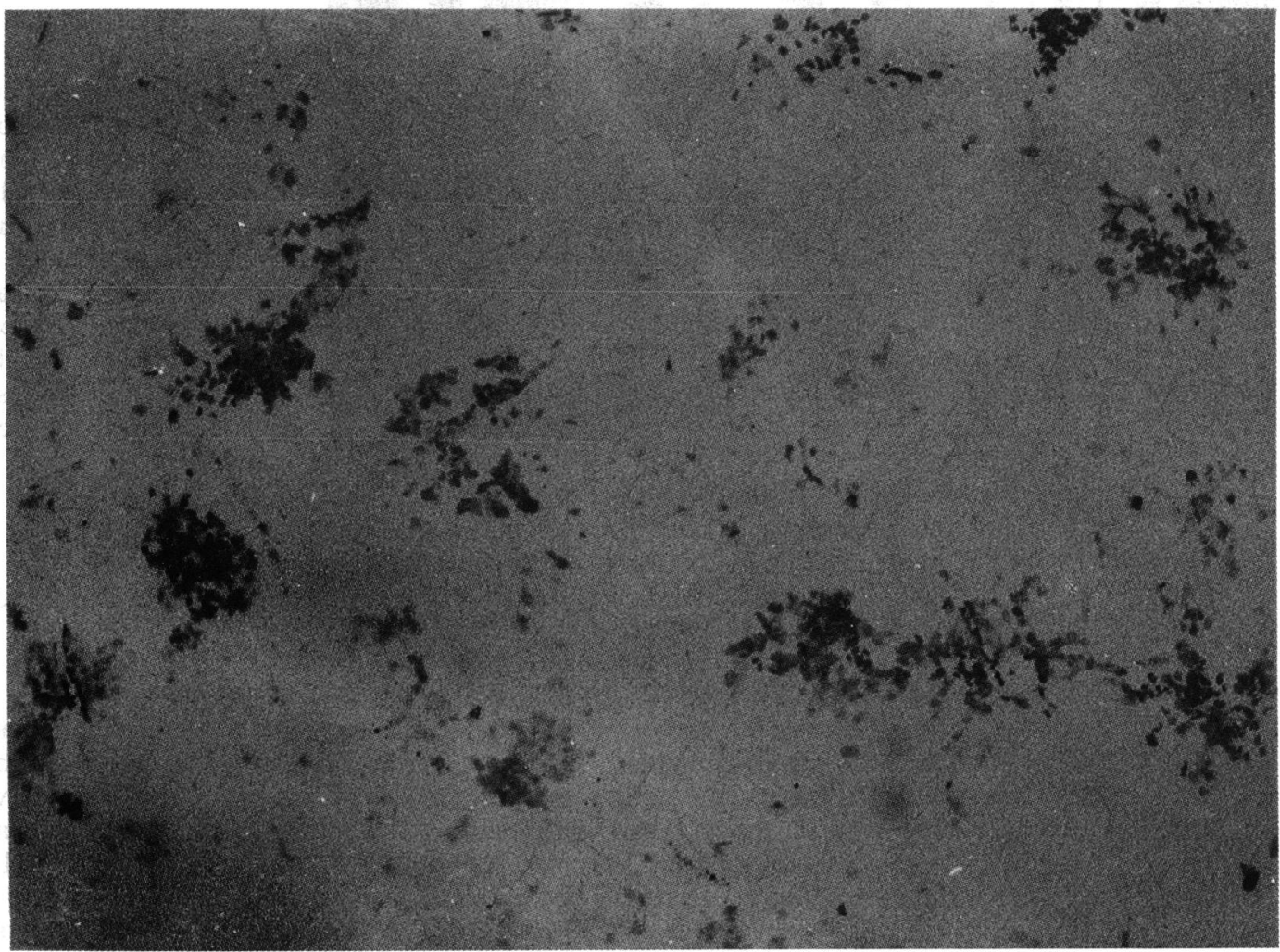




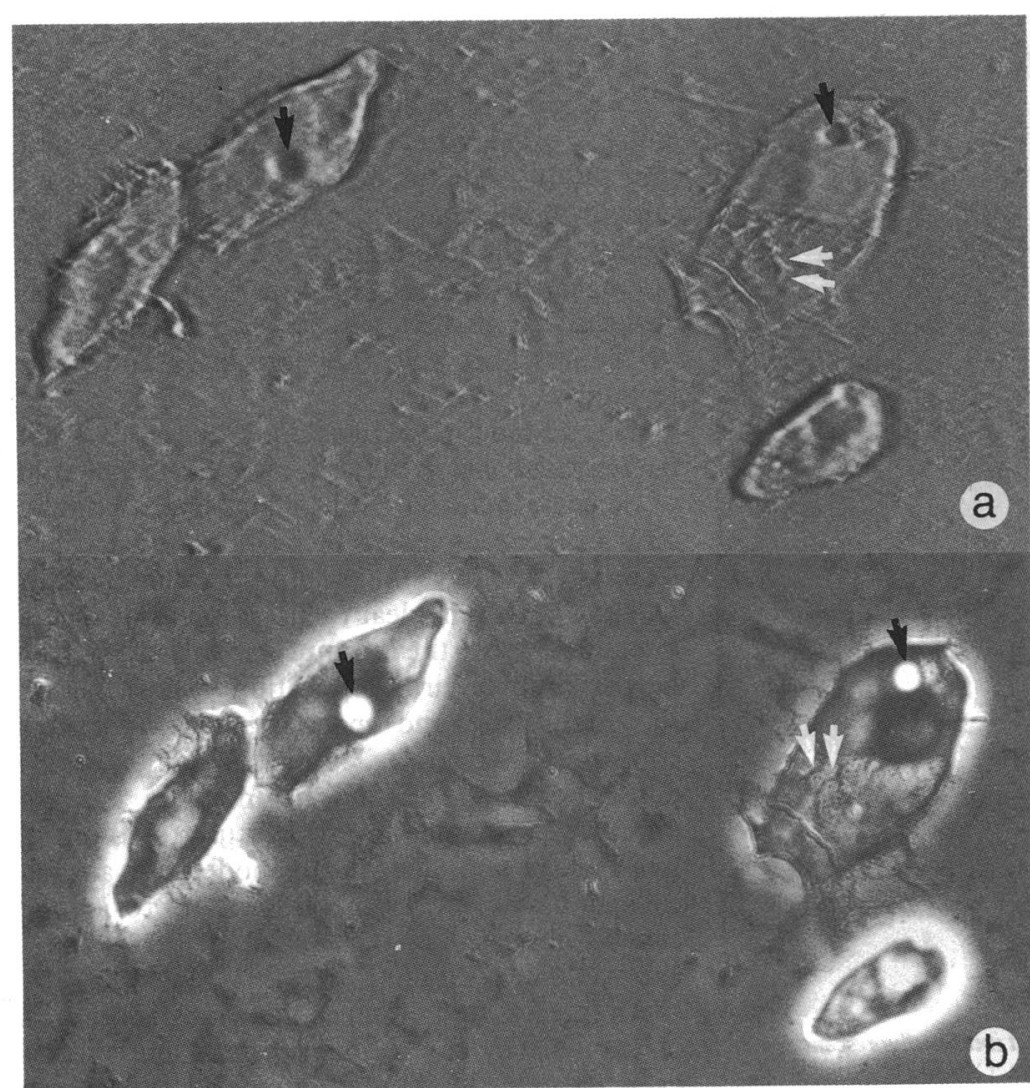

Figure 6 (a) Plicae (white arrow) and protruberances (black arrow) on cell surface by oblique illumination microscopy. $(\times 720)(b)$ Plicae appear as dark lines (white arrows) and areas of surface protruberances as cytoplasmic vacuoles (black arrows) by phase contrast microscopy. $(\times 720)$

fluorescence reaction (Fig 8), and showed the characteristics of DNA by other staining techniques (Fig 9). It appears that the development of intranuclear vacuolar inclusions, containing

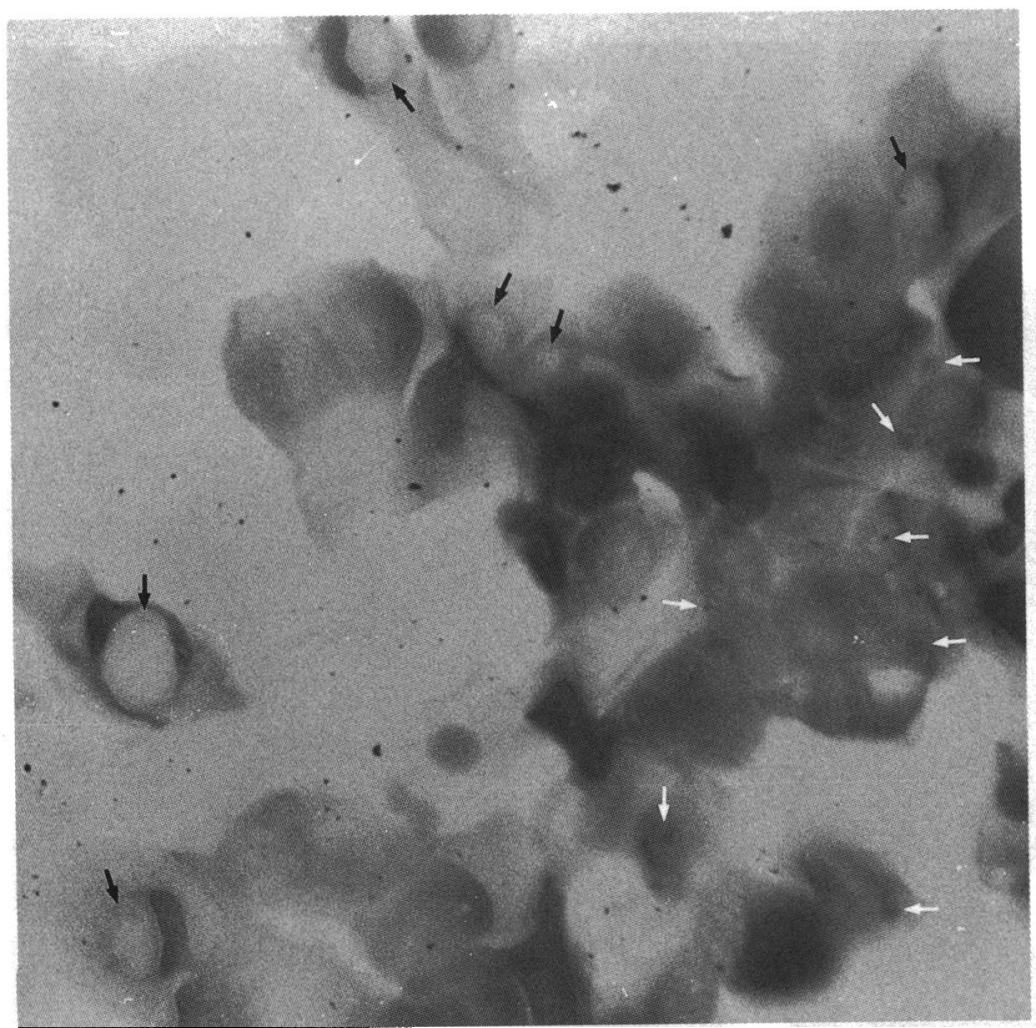

Figure 7 Intranuclear vacuolar inclusions (black arrows) present in many cells at the periphery of punctate lesion. Some round dense bodies (white arrows) are seen in the synctia and rounded epithelium cells. (Haematoxylin-eosin, $\times 720$ ) homogeneous material, is probably an initial step in virus replication, and the formation of round dense bodies represents the development of adenovirus. The round dense bodies measured from $1 \mu \mathrm{m}$ to $10 \mu \mathrm{m}$. In a few specimens round dense bodies were found in the extracellular spaces.

The swollen, globular cells in the punctate lesions also contained intranuclear vacuolar inclusions. However, round dense bodies were more frequently detected in these cells (Fig 9). Similarly, syncytia in the punctate lesions also contained round dense bodies. The central areas of some syncytia were necrosed, but the cell debris still contained a few dense round inclusion bodies.

Formation of pseudopodia-like processes from the syncytia was infrequently seen. When present, they were small, usually extending over two to five cell lengths. Leucocytes and ghost cells were not observed in our specimens.

\section{Discussion}

Duke-Elder ${ }^{10}$ summarised the corneal histopathological changes in epidemic keratoconjunctivitis as degenerative alterations in the corneal epithelium and stroma, with infiltration of mononuclear cells at the site of epithelial lesions. Bowman's membrane is thinned or even disappears. Lund and Stefani" described the corneal focal lesions in epidemic keratoconjunctivitis as a collection of polymorphs and mononuclear cells.

The predominant mononuclear cell response in the Giemsa stained conjunctival scrapings in our patients is in agreement with the findings reported in the literature. ${ }^{12}$

Replica histology of adenovirus keratitis shows mild diffuse oedema of the corneal surface epithelium. The ribonucleoprotein content of the cells is increased, the increase probably induced by the synthesis and accumulation of virus specific proteins. Conversely, some cells show loss of cytoplasm and nuclei, with resulting formation of plicae on the cell surface of shrunken empty envelopes of cell membranes. More affected cells, showing moderate swelling and alterations in their shape and size, are found scattered among the less oedematous cells that still preserve their shape and size. Marked structural cellular changes are observed in the areas of punctate lesions. The cells vary in shape and size, having attained an oval or rounded form. They show a tendency to fuse together, resulting in syncytial formations. Parts of the syncytia undergo necrosis. Only rarely do small pseudopodia-like processes develop from the syncytia.

Although cell swelling, rounding, and syncytia formation also occur in herpes simplex virus keratitis, ${ }^{1689}$ there are distinct cytopathological dissimilarities between the punctate keratitis caused by adenovirus and by herpes simplex virus. The punctate lesions in herpetic keratitis are cytologically more focal in character, and they are always circumscribed by rows of elongated epithelial cells. ${ }^{9}$ Round the branches of a dendritic figure the elongated cells are arranged in an arcuate pattern. ${ }^{89}$ We have not observed the presence of elongated cells in any other type 


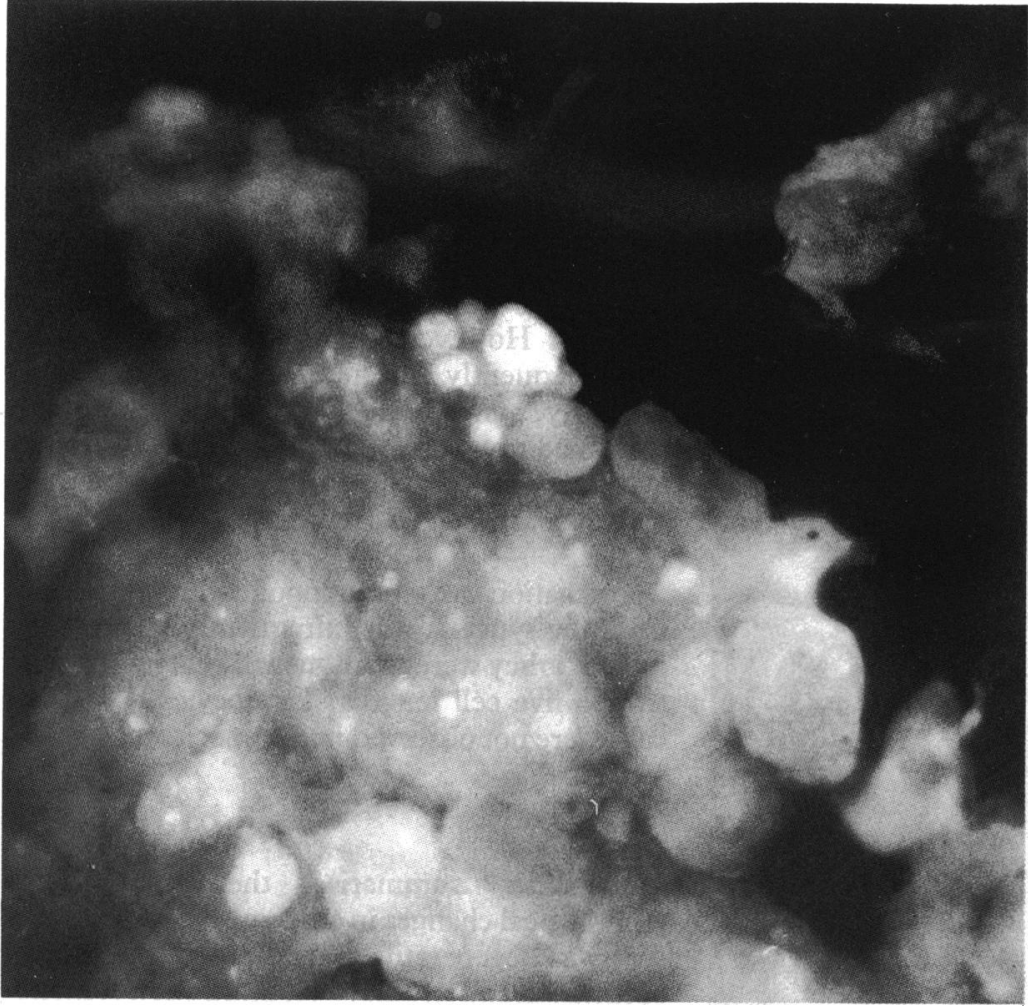

Figure 8 Round dense bodies exhibit a bright fluorescence by direct immunofluorescence technique to detect adenovirus. Note the variable size of dense bodies. $(\times 720)$

of epithelial keratitis. The syncytia in HSV infection are larger than in adenovirus keratitis. Equally, the pseudopodia-like processes are more numerous and larger in HSV punctate and dendritic keratitis, whereas in adenovirus keratitis they are rarely seen. The formation of plicae on the cell surface and loss of cell contents is, however, more frequent in adenovirus disease.
Ghost cells, present in HSV infection, ${ }^{68}$ were not found in adenovirus keratitis.

Two types of inclusions were detected in this study of adenovirus epithelial disease. The first type of intranuclear vacuolar inclusions containing homogeneous material develop commonly in the moderately altered cells. The homogeneous material in these inclusions is not antigenic in character as judged from the lack of fluorescence by the immunofluorescence technique.

The second type of inclusions are round dense bodies that develop in the homogeneous material of vacuolar inclusions. The dense bodies contain viral antigens, as shown by immunofluorescence technique and have the staining characteristics of DNA. The intranuclear vacuolar inclusions seem to be analogus to the intranuclear A-bodies of the herpes simplex virus replication cycle, wherein the replicating and maturing virus particles appear as A-granules. ${ }^{15}$ However, the round dense bodies in adenovirus infection are not granular. They measure from $1 \mu \mathrm{m}$ to $10 \mu \mathrm{m}$ in size and are abundant in the moderately altered cells and syncytia. In the areas of necrosis they can be observed in the cell debris or even in extracellular positions.

An interesting finding in this study is the lack of any leucocytes in the superficial epithelium, even though abundant lymphocytes and some polymorphs are found in the conjunctival scrapings. Similarly leucocytes have not been observed in the replicas from herpetic dendritic ulcers or punctate keratitis. ${ }^{89}$ Probably the lymphocytes and mononuclear cells penetrate into the deeper epithelial layers, and into the subepithelial stroma, owing to accumulation of viral antigens at these sites. ${ }^{11} 1314$

After making the corneal replica, epithelial

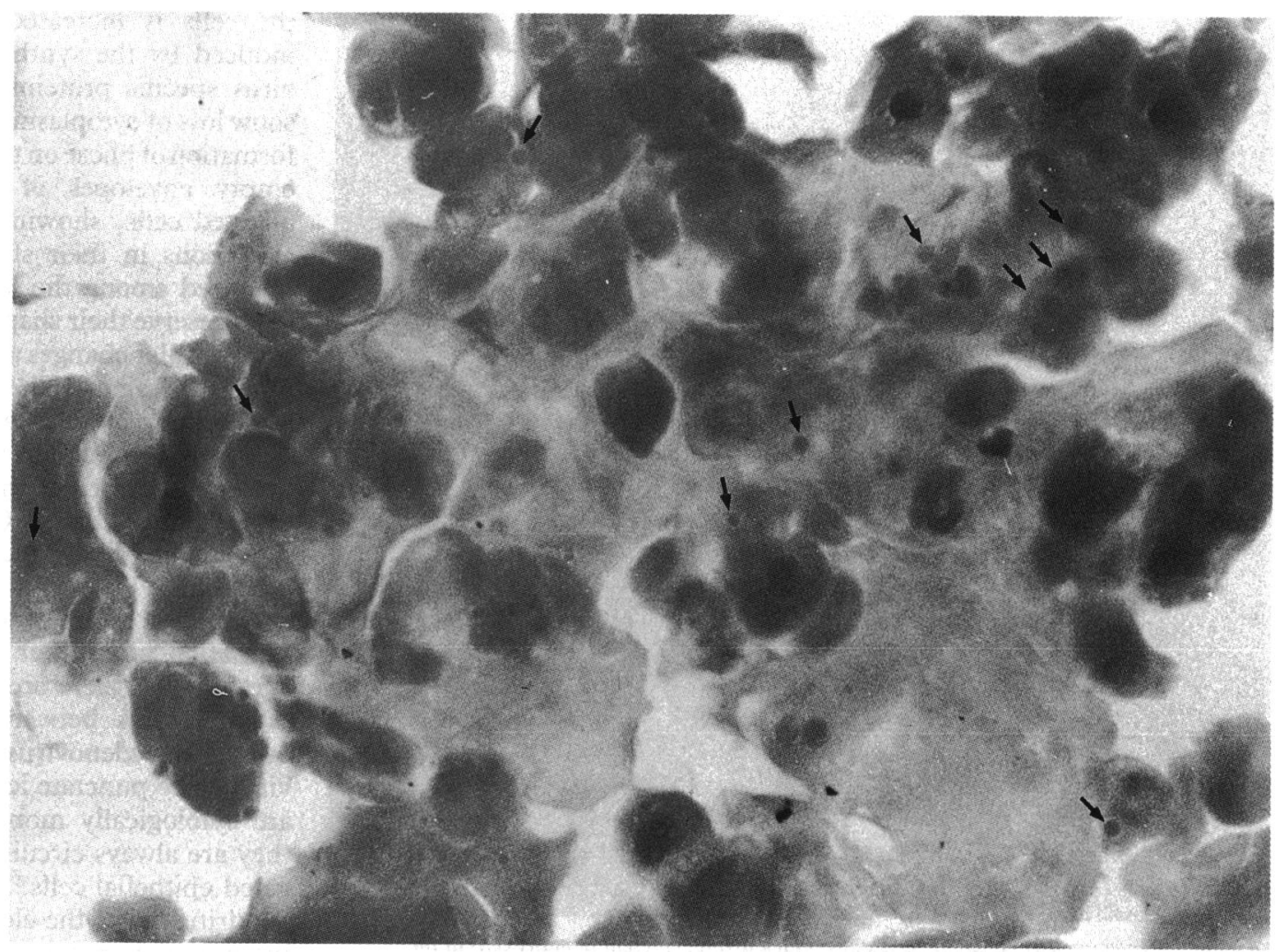

Figure 9 In the central parts of the punctate lesions the round dense bodies (some indicated by arrows) are abundant in the markedly altered cells. The staining pattern of inclusion bodies is that of nuclear DNA. (Haematoxylin-eosin, $\times 720)$ 
lesions did not form in the regenerated epithelium in most cases, nor in these cases did subepithelial opacities develop. Since amyl acetate, used to dissolve collodion in the replica solution, penetrates into the superficial stroma ${ }^{1-3}$ and kills the cells by fixation, the multiplying virus in the epithelium is probably destroyed by making the replica. Consequently the source of viral antigen which normally incites the mononuclear cell infiltration, resulting in development of subepithelial opacities on the basis of immune action, is eliminated. ${ }^{13-15}$

Making a corneal replica in adenovirus eye infection is not only a diagnostic aid: it may also be a therapeutic measure. The therapeutic effect of the replica technique in dendritic ulcers has been reported elsewhere. ${ }^{16}$

1 Maudgal PC. The epithelial response in keratitis sicca and keratitis herpetica. An experimental and clinical study. Doctoral thesis, University of Leuven, 1976. Doc Ophthalmol 1978; 45: 223-327.

2 Missotten L, Maudgal PC. The corneal replica technique used to study the superficial corneal epithelium in vivo. Am $\mathcal{F}$ Ophthalmol 1977; 84: 104-11.

3 Maudgal PC, Missotten L. Superficial keratitis. Bull Soc Belge Ophtalmol 1980; 187: 2-6.
4 Maudgal PC, Missotten L. Histology and histochemistry of the normal superficial corneal epithelium of rabbit. Graefes Arch Clin Exp Ophthalmol 1978; 205: 167-74.

5 Maudgal PC, Missotten L. Development of disseminating inclusion bodies in primary experimental herpes simplex inclusion bodies in primary experimental herpes sim

6 Maudgal PC, Missotten L. Histopathology and histochemistry of the superficial corneal epithelium in experimental herpes simplex keratitis. Graefes Arch Clin Exp Ophthalmol 1979; 209: 239-48.

7 Love R, Wildy P. Cytochemical studies of the nucleoproteins of HeLa cells infected with herpes virus. $\mathcal{F}$ Cell Biol 1963; 17: 237-54.

8 Maudgal PC, Missotten L. Histopathology of human superficial herpes simplex keratitis. $\mathrm{Br} \mathcal{F}$ Ophthalmol 1978; 62 . 46-52.

9 Maudgal PC, Missotten L. Histopathological study of the human herpes simplex dendritic and punctate keratitis by replica technique. Doc Ophthalmol Proc Ser 1979; 20: replica

10 Duke-Eider S. Diseases of the outer eye System of ophthalmology. London: Kimpton, 1965: 8: (1): 352-8.

11 Lund OE, Stefani FH. Corneal histology after EKC. Arch Ophthalmol 1978; 96: 2085-8.

12 Vastine DW, Wilmer BI. Adenoviridae. In: Darrell RW, ed. Viral diseases of the eye. Philadelphia: Lea and Febiger, 1985: $131-46$.

13 Dawson CR, Hanna L, Togni B. Adenovirus type 8 infections in the USA. IV. Arch Ophthalmol 1972; 87: 258-68.

14 Periera HG. Persistent infection by adenoviruses. $f$ Clin Pathol 1972; 25 (suppl 6): 39-42.

15 Jones BR. The clinical features of viral keratitis and a concept of their pathogenesis. Proc $R$ Soc Med 1958; 51: 13-20.

16 Maudgal PC, Van Deuren H, Missotten L. Therapeutic effect of corneal replica in herpetic keratitis. Bull Soc Belge Ophtalmol 1979; 185: 39-46. 